\title{
Frequentie en kwaliteit van feedback tijdens blok I in de huisartsopleiding aan de $\mathrm{VU}$
}

\author{
Locher G, Rhijn van SM, Verdegaal CA
}

\section{Samenvatting}

Inleiding: Leren leren is een belangrijk doel van geneeskundeopleidingen. Feedback is een didactisch instrument om dit te stimuleren. In de huisartsopleiding aan de VU (HOVU) is gepeild wat de huisartsen-in-opleiding (HAIO's) vinden van de frequentie en de kwaliteit van de feedback op de terugkomdagen en op de stageplek.

Methode: De antwoorden van 36 HAIO's op de vragen over feedback op medisch handelen, functioneren in de praktijk en functioneren als leerling uit de reguliere evaluatie van blok 1 in 1999/2000 werden geanalyseerd.

Resultaten: De respons was ongeveer $80 \%$. De frequentie van de feedback was tijdens de terugkomdagen laag op aspecten van medisch handelen. De frequentie scoorde op de stageplek hoger dan tijdens het terugkomdagonderwijs. De kwaliteit van de feedback scoorde het hoogst op de stageplek, met uitzondering van het maken van een leerplan. De hoogste score voor kwaliteit werd gegeven voor consultvaardigheden tijdens het terugkomdagonderwijs.

Discussie: De HAIO's lijken zowel de frequentie als de kwaliteit van de feedback redelijk te vinden. De hoogste waardering krijgt de feedback op de stageplek op het medisch handelen en functioneren in de praktijk. De HAIO's lijken meer en op sommige onderdelen betere feedback te willen op medisch handelen tijdens de terugkomdagen. Op de stageplek is de kwaliteit van feedback op het maken van een eigen leerplan zeer laag. Vervolgonderzoek met een scherpere omschrijving van feedback kan meer inzicht opleveren. (Locher G, Rhijn SM van, Verdegaal CA. Frequentie en kwaliteit van feedback tijdens blok 1 in de huisartsopleiding aan de VU. Tijdschrift voor Medisch Onderwijs 2002; 21(1):18-24.)

\section{Inleiding}

In de latere beroepspraktijk moet een arts zich blijven ontwikkelen en nieuwe dingen leren. Dit betekent dat studenten tijdens hun opleiding moeten leren leren. Voorwaarde hiervoor is dat zij leren reflecteren, zowel op het vakmatig handelen als op de manier waarop zij leren. ${ }^{1}$ Een sterk didactisch middel om studenten te stimuleren tot reflectie is feedback. ${ }^{1}$ Feedback geeft studenten informatie over in hoeverre zij zich in de goede richting ontwikkelen en goed functioneren. Het is belangrijk dat studenten weten hoe zij ervoor staan wat betreft kennisverwerving en het aanleren van vaardigheden. ${ }^{2}$ Uit onderzoek is gebleken dat feedback het leren van vaardigheden, zoals lichamelijk onderzoek, kan bevorderen. ${ }^{3}$ Kortom, feedback wordt gezien als een nuttige didactische aanpak in het medisch onderwijs. Het is echter niet altijd even duidelijk wat onder feedback verstaan moet worden en wat de beste manier is om feedback te geven. Uit een onderzoek bleek dat stafleden en studenten verschillende opvattingen kunnen hebben ten aanzien van de feedback in dezelfde onderwijssituatie. De stafleden dachten vaker dat zij goede feedback gaven dan de studenten vonden dat zij goede feedback ontvingen. ${ }^{4}$ Daarnaast is uit onderzoek 
gebleken dat de frequentie en de kwaliteit van feedback in gezondheidszorgopleidingen soms te wensen overlaat. ${ }^{6}$ Het is dan ook belangrijk om na te gaan of de feedback die studenten krijgen wel aan de verwachtingen voldoet.

Gezien het belang dat wij in de huisartsopleiding aan de VU in Amsterdam (HOVU) hechten aan feedback leek het ons zinvol de meningen van de huisartsen-in-opleiding (HAIO's) over frequentie en kwaliteit van feedback aan een nader onderzoek te onderwerpen. In de huisartsopleiding is het leren leren een belangrijk uitgangspunt. Er wordt in de opleiding dan ook naar gestreefd dat de HAIO's voldoende en adequate feedback krijgen om hun leerproces te stimuleren. Om de evaluatie in de juiste context te plaatsen, geven wij eerst een korte beschrijving van de opleiding. Hierbij ligt de nadruk op het eerste blok van de opleiding, omdat in dit artikel de meningen van de HAIO's over de feedback in dit blok beschreven worden.

In het leerplan van de HOVU wordt de opleiding als volgt gekarakteriseerd: "De huisartsopleiding is in de eerste plaats een opleiding in en gericht op de praktijk. (...) In de huisartspraktijk ligt de nadruk op het opdoen van ervaringen en het uittesten van nieuw gedrag. Het leren op de afdeling en de zelfstudie bieden een mogelijkheid tot verdieping van het praktijkonderwijs. Tijdens de terugkomdag op de afdeling gaat het vooral om reflectie, begrip en theorie, maar ook om ervaring en experimenteren."7 De huisartsopleiding bestaat uit drie blokken, die elk een jaar duren. ${ }^{7}$ In het eerste blok lopen de HAIO's stage in een huisartspraktijk en daarnaast volgen zij één dag per week onderwijs op de afdeling huisartsgeneeskunde. In het eerste blok is het onderwijs op de afdeling gericht op elementaire kennis en vaardighe- den betreffende veel voorkomende klachten en ziekten. Aan de orde komen kennis en vaardigheden op het gebied van consultvoering, toetsing en wetenschappelijke vorming en een eerste oriëntatie op samenwerking en praktijkvoering. Tevens wordt gewerkt aan het bespreekbaar maken van de eigen houding, normen en waarden in relatie tot het werken als huisarts, met andere woorden het leren reflecteren op het eigen functioneren. Op de stageplek krijgen de HAIO's individuele feedback van hun huisarts-opleider (HAO) en tijdens de terugkomdagen wordt door de groepsbegeleiders feedback gegeven.

Om inzicht te krijgen in de mening van de HAIO's over de feedback, zijn de antwoorden geanalyseerd op de vragen over feedback uit de evaluatie van het eerste blok. We hebben een antwoord gezocht op de volgende vragen: Wat vinden de HAIO's van 1) de frequentie en 2) de kwaliteit van de feedback die zij hebben gekregen in het eerste blok, zowel tijdens de terugkomdagen op de afdeling huisartsgeneeskunde als op de stageplek?

\section{Methode}

Om antwoord te geven op de vragen over frequentie en kwaliteit van de feedback zijn gegevens uit de reguliere evaluatie gebruikt. We hebben de gegevens geanalyseerd van drie groepen van twaalf HAIO's die in maart 1999 gestart zijn met de HOVU. Het betrof de vragen over feedback uit de vragenlijst die de HAIO's in januari 2000 invulden.

In de HOVU wordt in elk blok een vragenlijst aan de HAIO's voorgelegd waarin hun mening gevraagd wordt over het onderwijsprogramma. In de vragenlijst zijn aparte vragen opgenomen over de frequentie en de kwaliteit van de feedback. Omdat er grote verschillen bestaan tussen het leren op de stageplek en op de afdeling 
huisartsgeneeskunde wordt er onderscheid gemaakt tussen feedback tijdens de terugkomdagen en feedback op de stageplek.

Onder feedback wordt hier verstaan elk commentaar dat door de HAIO opgevat wordt als een spiegel voor diens handelen. Of de HAIO's deze brede definitie van feedback ook hanteren, is niet bekend. Uit opmerkingen van HAIO's over feedback komt naar voren dat veel commentaar als feedback ervaren wordt wanneer de HAIO's er uit op kunnen maken of en in hoeverre hun huisartsgeneeskundig handelen (of hun handelen in een systeem of in een groep) 'aan de maat is', een bijdrage levert aan de oplossing van een probleem, of de oplossing juist verder af brengt.

De vragen over feedback in de evaluatie zijn in drie categorieën opgedeeld.

- Het functioneren van de HAIO in contacten met patiënten: het medisch handelen; Er wordt gevraagd naar de mening van de HAIO's over feedback op: 1) consultvoering; 2) medische kennis; 3 ) medische vaardigheden; 4) het omgaan met patiënten; 5) het nemen van medische beslissingen.

- Het functioneren in de praktijk; deze categorie is niet onderverdeeld.

- Het functioneren als leerling: het leren leren; hierin wordt onderscheiden feedback op: 1) het omgaan met de HAO als leermeester; 2) zelfstandigheid bij het leren; 3) hanteren van zwakke kanten van de eigen leerstijl; 4) vaardigheid in het maken van een individueel leerplan.

De HAIO's wordt gevraagd om voor elk van de bovengenoemde tien onderdelen aan te geven:

a. in hoeverre zij vinden dat ze voldoende frequent feedback hebben gekregen. Zij geven dit aan op een schaal van 0 tot en met 3: 0 = geen feedback gehad, 1 = wel feedback gekregen maar te weinig, 2 = genoeg feedback gekregen, $3=$ te veel feedback gekregen.

b. of ze iets van die feedback geleerd hebben. Dit kunnen de HAIO's aangeven op een schaal van 0 tot en met 4: $0=$ niet van toepassing/geen feedback gekregen, 1 = had ik niets aan, 2 = had ik weinig aan, 3 = had ik redelijk wat aan, $4=$ had ik veel aan.

Voor dit onderzoek is van de antwoorden op de vragen over feedback de frequentie van de verschillende scores berekend. Als een HAIO aangaf dat een vraag niet van toepassing was, is dit opgevat als geen respons op de betreffende vraag. In dat geval is de score gelijkgesteld met geen score en is het antwoord van de HAIO op die vraag verder buiten beschouwing gelaten.

\section{Resultaten}

\section{Respons}

Er waren 29 ingevulde vragenlijsten, een respons van $80 \%$, hetgeen bevredigend kan worden genoemd. De respons verschilt per vraag en is over het algemeen lager bij vragen over de feedback op de terugkomdagen.

Frequentie van feedback tijdens het terugkomdagonderwijs en op de stageplek In tabel 1 staan de resultaten betreffende de door de HAIO's ervaren frequentie van feedback. De scores voor feedback op de categorieën medisch handelen en functioneren in de praktijk zijn op de stageplek hoger dan tijdens de terugkomdagen. Met name de scores voor feedback tijdens de terugkomdagen over medische kennis, medische vaardigheden en het nemen van medische beslissingen zijn laag. Voor het functioneren als leerling zijn de scores tij- 
Tabel 1. Mening van haio's over de frequentie van feedback tijdens het terugkomdagonderwijs en op de stageplek. Frequenties (\%) van de scores op de vierpuntsschaal: $0=$ geen feedback gehad, $1=$ te weinigfeedback gehad, 2 = genoeg feedback gehad, 3 = te veel feedback gehad.

Onderwerpen

Terugkomdagen

Respons

$\mathrm{N}$
Frequentie per score (\%)
Stageplek

Respons Frequentie per score (\%)

\begin{tabular}{lllllllll}
\hline 0 & 1 & 2 & 3 & $N$ & 0 & 1 & 2 & 3
\end{tabular}

\begin{tabular}{|c|c|c|c|c|c|c|c|c|c|c|}
\hline \multicolumn{11}{|l|}{ Medisch handelen } \\
\hline - Medische kennis & 23 & 0 & 52 & 48 & 0 & 28 & 0 & 7 & 89 & 4 \\
\hline - Medische vaardigheden & 25 & 0 & 60 & 40 & 0 & 28 & 0 & 11 & 85 & 4 \\
\hline - Consultvaardigheden & 29 & 0 & 31 & 69 & 0 & 28 & 0 & 14 & 82 & 4 \\
\hline - Omgaan met patiënten & 24 & 0 & 42 & 58 & 0 & 28 & 0 & 18 & 79 & 4 \\
\hline $\begin{array}{l}\text { Nemen van medische } \\
\text { beslissingen }\end{array}$ & 21 & 0 & 67 & 33 & 0 & 24 & 0 & 8 & 88 & 4 \\
\hline Functioneren in praktijk & 18 & 0 & 39 & 61 & 0 & 27 & 0 & 15 & 81 & 4 \\
\hline \multicolumn{11}{|l|}{ Functioneren als leerling } \\
\hline $\begin{array}{l}\text { - Omgaan met huisarts- } \\
\text { opleider }\end{array}$ & 22 & 0 & 27 & 73 & 0 & 22 & 0 & 32 & 68 & 0 \\
\hline $\begin{array}{l}\text { - Zelfstandigheid leren } \\
\text { - Hanteren zwakke }\end{array}$ & 18 & 0 & 33 & 67 & 0 & 22 & 0 & 32 & 68 & 0 \\
\hline kanten eigen leerstijl & 21 & 0 & 24 & 71 & 5 & 25 & 0 & 32 & 68 & 0 \\
\hline - Maken eigen leerplan & 23 & 0 & 39 & 52 & 9 & 23 & 0 & 61 & 39 & 0 \\
\hline
\end{tabular}

dens de terugkomdagen en op de stageplek ongeveer gelijk. Dit betekent dat ze vergeleken met de scores voor de twee andere categorieën op de terugkomdagen iets hoger zijn en op de stageplek lager.

\section{Kwaliteit van feedback tijdens het terug-} komdagonderwijs en op de stageplek

In tabel 2 worden de scores gepresenteerd die de HAIO's hebben gegeven voor de kwaliteit van de verkregen feedback. De kwaliteit van de feedback op de stageplek scoort in het algemeen hoger dan de kwaliteit van de feedback op de terugkomdagen met uitzondering van consultvaardigheden, hanteren van zwakke en sterke punten van de eigen leerstijl en het maken van een eigen leerplan. Scores 3 en 4 (heb ik redelijk wat aan gehad en heb ik veel aan gehad) komen het meest voor zowel tijdens de terugkomdagen als op de stageplek. Wel is het percentage studenten dat score 4 geeft op de stageplek veelal hoger dan tijdens de terugkomdagen. Verder zijn op de stageplek de scores in de categorie functioneren als leerling lager dan de scores op het functioneren in de praktijk en het medisch handelen. Op de terugkomdagen scoort medische vaardigheden erg laag en consultvaardigheden erg hoog.

\section{Discussie}

Een beperking van de gebruikte vragenlijst is dat de interpretatie van het begrip feedback geheel voor rekening van de HAIO's gelaten wordt. Er is niet gedefinieerd wat onder feedback wordt verstaan. Wij hadden bijvoorbeeld een hogere score verwacht op feedback be- 
Tabel 2. Mening van haio's over de kwaliteit van feedback tijdens het terugkomdagonderwijs en op de stageplek. Frequentie (\%) van de scores op de vierpuntsschaal: 1 = heb ik niets aan gehad; 2 = heb ik weinig aan gehad; 3 = heb ik redelijk wat aan gehad; $4=$ heb ik veel aan gehad.

\begin{tabular}{|c|c|c|c|c|c|c|c|c|c|c|}
\hline \multirow[t]{3}{*}{ Onderwerpen } & \multicolumn{5}{|c|}{ Terugkomdagen } & \multirow{3}{*}{$\begin{array}{c}\text { Stageplek } \\
\text { Respons } \\
\text { N }\end{array}$} & \multirow{2}{*}{\multicolumn{4}{|c|}{ Frequentie per score (\%) }} \\
\hline & \multirow{2}{*}{$\begin{array}{l}\text { Respons } \\
\qquad N\end{array}$} & \multicolumn{4}{|c|}{ Frequentie per score (\%) } & & & & & \\
\hline & & 1 & 2 & 3 & 4 & & 1 & 2 & 3 & 4 \\
\hline \multicolumn{11}{|l|}{ Medisch handelen } \\
\hline - Medische kennis & 21 & 0 & 33 & 57 & 10 & 28 & 0 & 11 & 43 & 46 \\
\hline - Medische vaardigheden & 24 & 4 & 38 & 50 & 8 & 28 & 0 & 4 & 39 & 57 \\
\hline - Consultvaardigheden & 28 & 0 & 0 & 39 & 61 & 28 & 4 & 7 & 46 & 46 \\
\hline - Omgaan met patiënten & 23 & 0 & 17 & 48 & 35 & 28 & 0 & 7 & 43 & 46 \\
\hline \multicolumn{11}{|l|}{ - Nemen van medische } \\
\hline beslissingen & 20 & 0 & 20 & 60 & 20 & 24 & 0 & 13 & 50 & 38 \\
\hline Functioneren in praktijk & 18 & 6 & 28 & 50 & 16 & 27 & 4 & 4 & 59 & 33 \\
\hline \multicolumn{11}{|l|}{ Functioneren als leerling } \\
\hline \multicolumn{11}{|l|}{ - Omgaan met huisarts- } \\
\hline opleider & 22 & 0 & 36 & 45 & 18 & 22 & 4 & 14 & 41 & 41 \\
\hline - Zelfstandigheid leren & 18 & 6 & 33 & 50 & 11 & 21 & 5 & 19 & 33 & 43 \\
\hline \multicolumn{11}{|l|}{ Hanteren zwakke } \\
\hline kanten eigen leerstijl & 21 & 0 & 5 & 71 & 24 & 25 & 4 & 16 & 40 & 40 \\
\hline - Maken eigen leerplan & 22 & 4 & 23 & 59 & 14 & 23 & 9 & 30 & 44 & 17 \\
\hline
\end{tabular}

treffende medische kennis op de terugkomdagen. De reden hiervoor was dat wij de Landelijke Huisartsgeneeskundige Kennistoets als feedback beschouwen. Deze toets wordt in blok I twee keer afgenomen. Het is een schriftelijke, zeer zorgvuldig samengestelde toets van medische kennis. Uit de resultaten valt evenwel niet op te maken of de HAIO's deze toetsen bij hun oordeel over de feedback betrokken hebben. Verder dient er bij het interpreteren van de resultaten rekening mee gehouden te worden dat de nadruk in dit onderzoek ligt op de subjectieve meningen van de HAIO's. Wij gaan nu in op beide onderzoeksvragen afzonderlijk.

\section{Vraagstelling 1.}

Wat vinden de HAIO's van de frequentie van de feedback die zij hebben gekregen in Blok I tijdens het terugkomdagonderwijs en op de stageplek?

De scores lijken een indicatie dat de meeste HAIO's de frequentie goed vinden. Kijkt men naar de frequentie van feedback op de stageplek, dan is de frequentie van de feedback op medisch handelen en het functioneren in de praktijk volgens de HAIO's voldoende, een enkeling vindt het zelfs te veel. Uit de scores in deze categorieën tijdens de terugkomdagen komt naar voren dat vrij veel HAIO's vinden dat ze te weinig feedback krijgen. Dit geldt met name voor medische kennis, medische vaardigheden en het nemen van medische beslissingen. Zoals hierboven aan- 
gegeven speelt hier mogelijk een rol dat de HAIO's de schriftelijke kennistoetsen niet opvatten als feedback. De lage score voor feedback op vaardigheden kan te maken hebben met het onvoldoende 'droog' oefenen van vaardigheden tijdens het terugkomdagonderwijs. De lage score voor het nemen van diagnostische en therapeutische beslissingen zou erop kunnen wijzen dat de HAIO's behoefte hebben aan meer patiëntenbesprekingen tijdens het terugkomdagonderwijs.

In de categorie functioneren als leerling vindt $24-61 \%$ van de HAIO's dat er te weinig feedback is gegeven. Tijdens de terugkomdagen lijkt de score iets gunstiger, maar de verschillen zijn klein. Op beide plaatsen lijkt verbetering mogelijk.

\section{Vraagstelling 2. \\ Wat vinden de HAIO's van de kwaliteit van de feedback die zij hebben gekregen in Blok I tijdens het terugkomdagonder- wijs en op de stageplek?}

De hoogste scores worden gegeven voor feedback op de stageplek op medisch handelen en functioneren in de praktijk. Wat opvalt in alle categorieën is dat op de stageplek score 4 en op de terugkomdagen score 3 het meest voorkomt. De waardering voor de kwaliteit van de feedback tijdens de terugkomdagen wisselt. De feedback op medische vaardigheden, functioneren in de praktijk en zelfstandigheid leren scoort laag. De scores voor het omgaan met patiënten, het nemen van medische beslissingen en het hanteren van de zwakke kanten van de eigen leerstijl zijn hoger. Consultvaardigheden levert de hoogste score voor kwaliteit van feedback op. Blijkbaar is het ook tijdens de terugkomdagen mogelijk feedback op medisch handelen te geven die door de HAIO's hoog gewaardeerd wordt. Op de stageplek scoort het medisch handelen hoger dan het functioneren als leerling. Dit is geen verrassing: huisartsopleiders zijn vooral geschoold in de huisartsgeneeskunde en kunnen dientengevolge ook goed letten op het huisartsgeneeskundig handelen. Hoewel daar wel hard aan wordt gewerkt, zijn HAO's niet in eerste instantie didactisch geschoold, waardoor ze minder aandacht zullen hebben voor het leren leren van hun stagiaires. Een duidelijke uitschieter naar beneden vormt het maken van een eigen leerplan. Het feit dat meer dan de helft van de HAIO's aangeeft hier weinig aan gehad te hebben kan erop wijzen dat de HAO's zich niet verantwoordelijk voelen voor dit onderdeel. Dit sluit mogelijk aan op een gebrek aan continuïteit in de leergesprekken, dat ook eerder is geconstateerd. ${ }^{8}$ Continuilteit betekent hier dat er bij het leergesprek wordt ingegaan op leerpunten die afgesproken zijn in eerdere leergesprekken of evaluaties en dat er bij het afsluiten van het gesprek nieuwe afspraken gemaakt worden. Op de terugkomdagen scoort het maken van een eigen leerplan wel hoger, maar toch vindt ruim een derde van de HAIO's dat ze hier weinig aan gehad hebben.

Er is een aantal verschillen tussen het terugkomdagonderwijs en de stageplek, dat misschien verklaart waarom in het algemeen de feedback op de stageplek leerzamer wordt gevonden dan die tijdens het terugkomdagonderwijs. Feedback op de stageplek gaat meer over wat de HAIO in de praktijk doet als huisarts dan feedback tijdens het terugkomdagonderwijs. Dit maakt de feedback wellicht in de ogen van de HAIO meer valide. Op de terugkomdagen zien de groepsbegeleiders de HAIO tegelijk met elf andere HAIO's. Dat maakt het moeilijker iedereen regelmatig aan bod te laten komen waardoor een gefundeerd oordeel ook langzamer tot stand komt dan op de stageplek. De feedback op 
de stageplek wordt gegeven in een één-opéén-relatie. In de meeste gevallen is zo'n relatie intensiever dan de relatie met elf andere groepsleden en een of twee begeleiders. Ook uit onderzoek is gebleken dat studenten individuele feedback hoog waarderen. ${ }^{9}$

De evaluatie geeft de indruk dat de HAIO's redelijk tevreden zijn. Toch lijkt er ook verbetering mogelijk. Om een goed beeld te krijgen hoe de feedback verbeterd kan worden, is het wenselijk om verder onderzoek te doen met een duidelijke omschrijving van feedback. Ook is het belangrijk om na te gaan of de mening van de HAIO's over feedback overeenkomt met die van de begeleiders. In een volgend artikel gaan we in op wat groepsbegeleiders aan feedback geven.

\section{Literatuur}

1. Peeters OL Spaendonck KPM van. Studenten leren nadenken over hun eigen functioneren. In: Metz JCM, Scherpbier AJJA, Vleuten CPM van der. Medisch onderwijs in de praktijk. Assen: Van Gorcum; 1995. p. 356-363.

2. Wood BP. Feedback: a key feature of medical training. Radiology 2000; 215:17-9.

3. Paul S, Dawson KP, Lanphear JH, Cheema MY. Video recording feedback: a feasible and effective approach to teaching history-taking and physical examination skills in undergraduate paediatric medicine. Med Educ 1998; 32:332-6.

4. Gil D, Heins M, Jones P. Perceptions of medical school faculty members and students on clinical clerkship feedback. J Med Education 1984; 59:856-64.

5. Westberg J, Jason H. Providing constructive feedback. A CIS guidebook for health professions teachers. Boulder, Colorado: (Centre for Instructional Support): Johnson Printing; 1991.

6. Menon S, Kalishman S. Student assessment. Acad Med 1998; 73:S46-S53.

7. Huisartsopleiding Vrije Universiteit. Leerplan Huisartsopleiding Vrije Universiteit maart 2001.hoofdstukken 3 en 4. Amsterdam, Vrije Universiteit, maart 2001

8. Slort W. Trainen van huisartsopleiders. Worden zij daar beter van? Het diabetesproject. Amsterdam Huisartsen Opleiding Vrije Universiteit. 1996.

9. Parikh A, McReelis K, Hodges B. Student feedback in problem based learning: a survey of 103 final year students across five Ontario medical schools.

\section{De auteurs:}

G. Locher is gedragswetenschappelijk medewerker aan de huisartsenopleiding VU.

S.M. van Rhijn is huisartsbegeleidster aan de huisartsenopleiding $V U$.

C.A. Verdegaal is nu huisarts, maar ten tijde van het onderzoek derde jaars HAIO aan de huisartsopleiding VU.

\section{Correspondentieadres:}

G. Locher, Huisartsopleiding Vrije Universiteit, Overschiestraat 180, 1062 XK Amsterdam.

\section{Summary}

Introduction: Learning to learn is an important goal of medical education. Feedback is a didactic tool to stimulate this. The perceptions of GP trainees at the school for general practice, Vrije Universiteit, Amsterdam, regarding the frequency and quality of feedback received from their GP tutors and teachers at the school for general practice were investigated.

Method: The results of the items on feedback regarding functioning as a GP, functioning as a member of the practice organisation, and functioning as a student from the course evaluation at the end of the first year of GP training were analysed.

Results: The response was $80 \%$. The perceived frequency of feedback from the teachers at the school for general practice was low for aspects of functioning as a GP. The frequency of feedback from the GP tutors scored more highly. The quality of feedback from the GP tutors received the highest scores, except for individual educational planning. The feedback on consultation skills at the school for general practice received the highest rating for quality.

Discussion: The GP trainees appear to be reasonably satisfied with the frequency and quality of the feedback they receive. The highest appreciation is expressed for the feedback on functioning as a GP from the GP tutors. More feedback appears to be desired on aspects of functioning as a GP during the sessions at the school. Low scores on educational planning may indicate a need for didactic training of GP tutors. Future studies using a clear definition of feedback may provide more insight. (Locher G, Rhijn SM van, Verdegaal CA. Feedback during the first year of general practice training. Dutch Journal of Medical Education 2002; 21(1):18-24.) 